\title{
HISTORIA DE LAS MUJERES, SABER DE LAS MUJERES: LA INTERPRETACIÓN DE LAS FUENTES EN EL MARCO DE LA TRADICIÓN FEMINISTA
}

Ma DOLORES RAMOS

Universidad de Málaga

\section{SOBRE INDICIOS, HUELLAS Y MATERIALES}

Las mujeres han contribuido, con sus trabajos, esfuerzos y responsabilidades, a la construcción del mundo. Han sido agentes de cambio en la Historia y han participado en la transmisión de la memoria colectiva, aunque, paradójicamente, el discurso histórico no las haya tenido en cuenta hasta un pasado relativamente reciente ${ }^{1}$. La Historia Universal, la Grande y General Historia, no ha sido más que un registro parcial del ayer escrito desde un punto de vista pretendidamente aséptico, sesgado, que potenciaba entre otras exclusiones las de clase, género y etnia, funcionando como un elemento legitimador a la hora de transmitir los códigos normativos que permitían tales exclusiones ${ }^{2}$. No en vano los sistemas de poder se reproducen, según Dolores Juliano, «mediante la acción (consciente o no) de un agente desvalorizado del sistema [en este caso la mujer], que al actuar como agente reproductor de la ideología dominante autorreproduce su propia desvalorización» ${ }^{3}$.

Hace unos años Gerda Lerner recurrió a la metáfora para explicar la «dimensión unidimensional» con la que han sido construidas las ciencias sociales y humanas en el ámbito de la cultura patriarcal: «Cuando miramos sólo con un ojo -subrayaba- nuestro campo de visión es limitado y carece de profundidad. Si miramos luego con el otro, nuestro campo visual se amplía pero todavía le falta profundidad. Sólo cuando abrimos los dos ojos a la vez logramos tener todo el campo de visión y una percepción exacta de la profundidad ${ }^{4}$. Dicho de

1. LERNER, Gerda: La creación del patriarcado. Barcelona, Crítica, 1990, p. 20.

2. FONTANA, José: La Historia de los hombres. Barcelona, Crítica, 2001.

3. JULIANO, Dolores: «Ámbito doméstico y autorreproducción social», en V. Maquieira; G. Gómez-Ferrer; M. Ortega (eds.): Mujeres y hombres en la formación del pensamiento occidental, Madrid, Ediciones de la Universidad Autónoma de Madrid, 1989, vol. II, pp. 35-50.

4. LERNER, Gerda: op. cit., p. 20. 
otra forma: sólo cuando la visión femenina es igual a la masculina percibimos las verdaderas relaciones existentes entre todo el conjunto. Lo que subyace $-\mathrm{y}$ lo que emerge también- a partir de estas consideraciones es la imperiosa necesidad de redefinir la Historia y explicar qué es un hecho histórico. Lo que subyace y emerge -a la vez- es la necesidad de saber qué tipo de Historia se escribirá cuando mujeres y hombres compartan por igual la tarea de hacer definiciones y se sustituyan unas categorías analíticas por otras, cuando se asuma de una vez por todas que el Hombre en abstracto no es la medida de todo lo humano: lo son las mujeres y los hombres, con sus identidades segmentadas por la incidencia de diversos elementos. Ello presupone una innovación del conocimiento que no puede concebirse al margen de la teoría feminista, considerada en sus plurales vertientes interpretativas y analíticas. En este sentido, la Historia de las Mujeres ha roto barreras epistemológicas, disciplinarias y geográficas para dar pie a «tradiciones nacionales» acordes no sólo con la trayectoria seguida por los feminismos históricos y los feminismos contemporáneos en algunos países, marcados por componentes de clase, étnicos, religiosos, sino con las vicisitudes de los Women's Studies, y la evolución -en un marco más general- de las escuelas historiográficas, e incluso con la peripecia académica, política, social y personal de las mujeres que han hecho suya la causa feminista.

Tradicionalmente la historiografía ha entendido la historia de la humanidad como sinónimo de determinadas formas de poder ligadas, por presencia y ausencia, al colectivo social masculino. Sin embargo, si dejamos en suspenso la premisa de la universalidad del proyecto ilustrado y su teoría del Poder, comprobamos que éste no es significante porque el hecho de no tenerlo puede ser en determinados contextos y para ciertos sujetos, un hecho irrelevante, no significativo ${ }^{5}$. La pretendida línea de progreso que difundió la Ilustración cuenta con demasiados dientes de sierra, desvíos y fronteras, una cuestión en la que la crítica feminista viene a coincidir con otras teorías críticas. Esta perspectiva nos lleva a considerar la diferencia entre un individualismo abstracto, que requiere, a la hora del mutuo reconocimiento entre iguales, la exclusión de lo Otro, de lo privado, de los afectos y emociones; y un individualismo concreto, no universalizable, que no es otro que el "desorden de lo privado" al que han sido adscritas las mujeres ${ }^{6}$. Dualidad que no puede ser correctamente entendida sin relacionarla con otro de los grandes ejes de la concepción liberal de la ciudadanía: la distinción entre la esfera pública y la privada. En este sentido, siguiendo la línea argumental de Celia Amorós , el espacio público es el espacio de los

5. RIVERA GARRETAS, Milagros: «La Historia de las mujeres ¿es hoy la Historia?», en C. Segura Graiño, (ed.), La Historia de las mujeres en el nuevo paradigma de la Historia, Madrid, Asociación Cultural Al-Mudayma, 1997, pp. 64-66.

6. BENHABIB, Sheila: «El otro generalizado y el otro concreto: la teoría Kolberg-Killigan y la teoría feminista", en Sh. Benhabib; D. Cornell: Teoría feminista y teoría crítica. Valencia, Alfons el Magnànim, 1990, p. 96.

7. AMORÓS, Celia: Tiempo de feminismo. Sobre feminismos, proyecto ilustrado y postmodernidad. MadridValencia, Cátedra-instituto de la Mujer-Universidad de Valencia, 1997. 
iguales -o de los que creen serlo-, de los que se reconocen como ciudadanos, un ámbito donde el poder se distribuye y se compite por él, mientras que el espacio privado es el que habitan las idénticas, así denominadas porque están llamadas a compartir un destino similar que les niega el reconocimiento de su individualidad y que no las reconoce como ciudadanas. Como puede observarse, el género establece en la teoría política una importante polaridad en torno a la distinción público-privado, y esa distinción se proyecta en ambas esferas mediante virtudes cívicas, disposiciones y actividades opuestas: autonomía/dependencia, justicia/solidaridad, derechos/cuidados. Un universo antinómico que contribuye a preservar los intereses de la esfera pública, de la que se excluyen las necesidades y los afectos para primar las estructuras y los aspectos jurídicos.

Michel Foucault, «historiador» de los poderes modernos, subraya también, desde otro ángulo, la importancia concedida a la privacidad y las estrategias comunitarias en el funcionamiento de las redes capilares del poder. El cuerpo individual es un reflejo del cuerpo social. Si los defensores del orden constituido postulan que sólo la clase dominante es capaz de conformar un cuerpo social sano, todos los demás grupos sociales deberán someterse a un proceso de asepsia ideológica para integrarse en el sistema. Por eso es preciso "vigilar y castigar", separar por clases, separar por edades, separar por sexos, encerrar a los desviados, ocultar la pobreza, sacralizarla después. ¿Conviene transformar la pobreza en locura? ¿La locura es pobreza? He aquí algunas de las estrategias del saber, una muestra de cómo funcionan las redes capilares del poder ${ }^{8}$. El estudio de las formaciones sociales y de sus representaciones culturales subraya, pues, aunque no se reconozca, una historia de las fronteras entre lo público y lo privado, de lo secreto, y a contraluz, de las personas que guardan el secreto, de aquellas otras que poseen el saber o que detentan un poder no institucional. El sacerdote, el notario y el médico constituyen claros arquetipos de este último durante la España decimonónica y buena parte del siglo XX. No en vano religiosidad, propiedad y corporeidad constituyen tres grandes pilares de las experiencias históricas cotidianas9. Este hecho invita a considerar el poder y la autoridad como dos conceptos diferentes, incita a estudiar la génesis y evolución de las genealogías y las voces femeninas de autoridad, frecuentemente borradas o difuminadas de las tradiciones culturales por ser éstas patriarcales, así como a reconocer la importancia de unas formas de conocimiento -sabiduría, maestría, mecenazgo- que contribuyen a redefinir la esfera política y lo público en genera $1^{10}$.

8. FOUCAULT, Michel: Microfísica del poder, $2^{\text {a }}$ ed., Madrid, La Piqueta, 1980

9. RAMOS, María Dolores, Mujeres e Historia. Reflexiones sobre las experiencias vividas en los espacios públicos y privados. Málaga, Atenea-Universidad, 1993.

10. Ver BOCHETTI, Alexandra: Lo que quiere una mujer. Historia. Política. Teoría. Escritos, 1981-1995, Madrid-Valencia, Cátedra-Instituto de la Mujer-Universidad de Valencia, 1996; RIVERA GARRETAS, Milagros: Nombrar el mundo en femenino. Pensamiento de las mujeres y teoría feminista, Barcelona, Icaria, 1994. LAURETIS, Teresa de: Diferencias. Etapas de un camino a través del feminismo, Madrid, Horas y Horas, 2000. 
Mas para desarrollarse, la Historia de las mujeres ha tenido que afrontar un difícil reto: el «espinoso tema de las fuentes». Ha tenido que valorar indicios, catalogar materiales, interpretar documentos, confrontarlos, cruzarlos. Durante bastante tiempo esos materiales se convirtieron en una cuestión central -hablando en términos políticos y científicos- del debate historiográfico. Una cuestión que podría sintetizarse en estos términos. O faltaban textos de mujeres -en los ámbitos académicos se subrayaba especialmente esta ausencia-, o bien abundaban los textos sobre las mujeres, pero en este caso era frecuente que cayeran en esencialismos, incomprensiones y caricaturizaciones sobre la feminidad, constituyendo uno de los más claros ejemplos de que el sujeto femenino, antes de que pudiera tomar la palabra y hablara de sí mismo, ya había sido "descrito", "hablado", "construido" por el Otro. El libro de Cristina de Pizán La ciudad de las damas, escrito en $1405^{11}$, da cuenta de esa profusión de discursos abriendo una de las primeras y más interesantes páginas de la Querella de las Mujeres o disputa de los sexos: una polémica filosófica, política y literaria desarrollada en Europa desde mediados del siglo XIII hasta finales del siglo XVIII sobre la inferioridad/ superioridad natural de mujeres y hombres ${ }^{12}$. Pizán se vio abocada a recolocar $\mathrm{y}$ «tallar las piedras»-los materiales discursivos- de su libro para levantar una Ciudad alegórica, un texto-recinto perfecto, ideal, en defensa de las damas, pues no en vano "durante mucho tiempo las mujeres han quedado... abandonadas como un campo sin cerca, sin que ningún campeón luche en su ayuda» ${ }^{13}$. Con la ayuda de las virtudes Razón, Rectitud y Justicia, la autora combate a escritores antiguos y coetáneos -entre ellos Jean de Meun, creador de la segunda parte del Roman de la Rose ${ }^{14}$ : una composición alegórica escrita en verso y tachonada de comentarios misóginos- y descubre las aportaciones filosóficas, literarias y científicas de numerosas mujeres a lo largo de la Historia. Pero el mortero y la tinta amalgamados de La Ciudad de las Damas no bastaron para acabar con las rancias y estrechas interpretaciones sobre la naturaleza femenina. El pensamiento ilustrado, aunque acogió en su seno, como si de una «hija natural» se tratara, una rama emancipista representada por mujeres y hombres-Madame d'Epinay, Condorcet, Olimpe de Gouges, Mary Wollstonecraft, Josefa Amar y Borbón, Ines Joyes- ${ }^{15}$, legitimó la dualidad Naturaleza/Cultura y siguió sin re-

11. PIZAN, Cristina de: La ciudad de las damas (Edición crítica a cargo de Ma José Lemarchand), Madrid, Ediciones Siruela, 1999.

12. Sobre la "Querella de las Mujeres» ver, RIVERA GARRETAS, Milagros: «La Querella de las Mujeres: una interpretación desde la diferencia sexual», Política y Cultura n6, 1996, pp. 25-39. VALCÁRCEL, Amelia: "La memoria colectiva y los retos del feminismo», en A. Valcárcel; M.D. Renau; R. Romero (eds.): Los desafios del feminismo ante el siglo XXI.,Sevilla, Instituto Andaluz de la Mujer, 2000.

13. PIZÁN, Cristina: op. cit., p. 69.

14. BADEL, Pierre-Yves: Le Roman de la Rose a u XIV siécle: étude de la réception de l'auvre, Ginebra, Droz, 1980.

15. Ver PULEO, Alicia (ed): Condorcet, de Gouges, de Lambert y otros. La Ilustración olvidada. La polémica de los sexos en el siglo XVIII, Madrid, Anthropos, 1993. WOLLSTONECRAFT, Mary: Vindicación de los derechos de la mujer (Edición de Isabel Burdiel), Madrid, Cátedra, 1994. AMAR y BORBÓN, Josefa: Discurso sobre la educación física y moral de las mujeres (Edición de Ma Victoria López 
conocer la presencia de las mujeres en la esfera pública. La Sofía de Rousseau es un punto de referencia. Cuando el filósofo, en el libro V de Emilio o la educación decide darle una compañera al protagonista, lo hace, retomando el lenguaje bíblico, para que "no esté solo». "Emilio es hombre. Le hemos prometido una compañera y es necesario dársela. Esta compañera es Sofía. ¿Dónde está su albergue? ¿En qué lugar la encontraremos? Es indispensable conocerla para poder encontrarla. Debemos saber primero lo que es, y cuando la encontremos, todavía no estará todo terminado» ${ }^{16}$.

En efecto, no es posible conocer la identidad de Sofía sin construirla primero. Ella está ligada al ámbito de la Naturaleza y todo a lo largo de su vida fértil se lo recordará constantemente. El elemento biológico predomina aquí sobre cualquier otro. En este discurso los hombres representan la ley, la voz, la palabra; las mujeres, la reproducción biológica y social, la educación de los hijos, el cuidado de la casa. Fiel a esta dualidad, en el transcurso del siglo XIX la ideología de la domesticidad va a configurar un modelo social de familia que emergerá con las revoluciones liberales y en el que sobresaldrá la figura del «ama de casa» como centro de la cultura doméstica burguesa.

"Mujeres enclaustradas ¿cómo podríamos encontraros?», escribía con una fina mezcla de ironía y ternura Michelle Perrot en su artículo «La mujer popular rebelde ${ }^{17}$. Evidentemente, no era fácil tropezarse con ellas en los espacios y escaparates del poder y el saber institucionalizados. Debido a los efectos de la segregación sexual y social y a la división de esferas, parecía que las mujeres no habían dejado grandes huellas de su paso por el ámbito público. Sin embargo, a pesar del silencio de la historia, o más bien de sus discursos, aquéllas sellaron su presencia en diferentes sociedades y épocas enarbolando «el bastón de paz que golpea a la injusticia», defendieron sus derechos a partir de "la regla de la justicia, que tiene muchas virtudes porque con ella pueden trazarse los límites de cualquier cosa...». Una regla útil para medir los edificios, "levantar los grandes templos, diseñar y construir calles y plazas, palacios, casas, alhóndigas (...) poblar una ciudad $»^{18}$. Librepensadoras y masonas tuvieron acceso a los instrumentos de medida y las herramientas de trabajo que formaban parte de la civitas recreada en el terreno de la escritura por Pizán. Lucharon por los derechos sociales y civiles. Otras mujeres reivindicaron los derechos políticos y sindicales, cubriéndose así todos los ámbitos de la ciudadanía. Centradas en estos objetivos, las mujeres tejieron sus propias redes. Pero la mirada de los

Cordón), Madrid, Cátedra, 1994. JOYES y BLAKE, Inés: El principe de Abisinia. Novela traducida del inglés por... Lleva inserta una Apología de las mujeres, en carta original de la traductora a sus hijas, Madrid, Sancha, 1798.

16. ROUSSEAU, Jean Jacques, Emilio o la educación, Barcelona, Bruguera, 1979. Ver RAMOS, María Dolores; VERA, Ma Teresa: «...Y Rousseau construyó a la mujer. (Palabras para una introducción), en M.D, Ramos; M.T. Vera (eds.), El trabajo de las mujeres. Pasado y presente, Málaga, 1996, vol. I, pp. 9-20.

17. PERROT, Michelle: «La femme populaire rebelle», en Ch. DUFRANCATEL et al., L'Histoire sans qualités. Essais, Paris, Editions Galilée, 1979.

18. PIZÁN, Cristina de: op. cit., p. 72. 
historiadores, enredada en otros asuntos, casi nunca las alcanzó. Alejadas de las prácticas sociales y políticas institucionales, las experiencias femeninas no engrosaron los materiales tradicionales de la Historia. Con todo, el silencio y la ausencia de testigos no siempre conspiraron contra las mujeres. En la esfera pública se apreciaban las huellas de un protagonismo vedado a la razón masculina, de escaso significado para la "democracia» excluyente ${ }^{19}$.

La documentación sobre las mujeres no sólo se resentía por este costado, sino que presentaba otro problema: frecuentemente era catalogada de acuerdo con unos criterios convencionales, nada acordes con las innovaciones conceptuales y metodológicas de los Women's Studies. Más o menos porosas, numerosas fuentes aun esperan ser descubiertas, interrogadas, interpretadas. Muchos materiales aún andan "perdidos", atrapados en medio de una gran masa documental. Algunos textos han sido sepultados, «sustraídos» a la mirada, borrados de la memoria. Françoise Thebáud ha denunciado la desaparición de numerosos legados en el Museo Social de París, refiriéndose a los informes sobre las militantes de izquierda que fueron recogidos y fechados por Erika Vincent antes de 1914. Mejor suerte corrieron los archivos femeninos sobre el período de entreguerras -correspondencia, recortes de prensa y libros reunidos por María Louise Bouglé- extraviados y posteriormente reencontrados e inventariados en la Biblioteca Histórica de París por Maite Albistur ${ }^{20}$. Recientemente, Luisa Isabel Álvarez de Toledo ensayaba una valoración de los fondos sobre mujeres albergados en el Archivo de la Casa Ducal de Medina Sidonia, en Sanlúcar de Barrameda ${ }^{21}$, destacando la importancia de los Fueros, las Ordenanzas y Reales Cédulas para determinar los derechos femeninos dentro y fuera del matrimonio, el interés de los libros de contabilidad a la hora de establecer el papel de las mujeres en los oficios y las actividades financieras (los contratos de arriendo, el pago y la percepción de rentas), la importancia de los epistolarios y memoriales, redactados directamente, o bien dictados a un secretario o amanuense, para reconstruir las trayectorias biográficas, para denunciar numerosas miserias, para detectar problemas sociales como el de las «mujeres maltratadas por los maridos, que piden al duque [de Medina Sidonia] la intervención de la justicia ${ }^{22}$.

Papeles personales, cartas, dietarios, libros de cuentas domésticas, colecciones de fotografías, diarios íntimos, memorias y autobiografías revelan diferentes vertientes de la experiencia histórica femenina, ya de manera abierta o bien en forma de "trazos furtivos». Así, los Archivos policiales muestran las desviaciones de las mujeres, sus faltas, su desobediencia al orden establecido.

19. FRAISSE, Genèvieve : Musa de la Razón. La democracia excluyente y la diferencia de los sexos, Madrid-Valencia, Cátedra-Instituto de la Mujer-Universidad de Valencia, 1991.

20. ALBISTUR, Maite: Catalogue des Archives Marie-Louise Brouglé. Thèse de troisième cycle sous la direction de Michèlle Perrot, Paris, Université Paris VII, 1982.

21. ÁLVAREZ DE TOLEDO Y MAURA, Luisa Isabel, Duquesa de Medina Sidonia: «El Archivo de Medina Sidonia: Un patrimonio escrito y conservado por mujeres», en Jornadas: La contribución de las mujeres al Patrimonio histórico, Córdoba, Diputación de Córdoba, Octubre 2002.

22. Ibídem. 
Los archivos judiciales no sólo hablan sobre las mujeres sino que hacen hablar a las mujeres. Por no hacer más larga la relación, en conjunto todos permiten una revalorización de la escritura y la palabra femenina. Igual que los testimonios orales, pues a partir de ellos se ha reconstruido la lucha de las mujeres antifranquistas en España y de las militantes de la Resistencia en Francia, así como numerosas historias de vida de las colaboracionistas durante la Segunda Guerra mundial. Se han rescatado importantes aspectos de la cotidianeidad; se han subrayado algunos de los trazos que conforman las identidades de género y las mentalidades colectivas ${ }^{23}$. En este recorrido cobra especial relieve el mundo de las imágenes: los cuadros, retratos, grabados, escenas de interior y de costumbres; la mirada fotográfica, fiel reflejo de las actitudes sociales, los espacios, las modas y normas de arreglo personal. Considerando otras cuestiones, el uso político de la imaginería femenina en la cartelería nos permite reflexionar sobre las representaciones, los símbolos y arquetipos utilizados, destacando entre ellos, de forma reiterada, los de la mujer-madre y la mujer-patria. La publicidad es un instrumento fundamental para entender cómo se construye la imagen social de las mujeres en la sociedad contemporánea. El cine no sólo entretiene y recrea, también socializa. La literatura, en fin, nos asoma a la vida cotidiana. ${ }^{24}$

El desarrollo de los estudios de género ha contribuido a que se publiquen catálogos bibliográficos ${ }^{25}$, recopilaciones de $\operatorname{textos}^{26}$ y un número cada vez mayor de revistas específicas, hecho que a su vez ha impulsado el desarrollo del conocimiento histórico sobre las mujeres en los espacios públicos y privados, en los sectores productivos y reproductivos, sin perder la noción del valor político que cabe conceder a unos y a otros ${ }^{27}$. Para Hélène Béjar «lo privado es

23. Ver GARCÍA NIETO, $\mathrm{M}^{\mathrm{a}}$ Carmen: La palabra de las mujeres. Una propuesta didáctica para hacer Historia 1931-1990. Madrid, Editorial Popular, 1991; ROMEU ALFARO, Mª Fernanda: El silencio roto. Mujeres contra el franquismo, $2^{a}$ ed., Madrid, El Viejo Topo, 2002; DÍAZ SÄNCHEZ, Pilar: El trabajo de las mujeres en el textil femenino. Racionalización industrial y experiencias de género (19591986), Málaga, Atenea-Estudios sobre la Mujer, 2001; AGUADO, Ana (coord.): Historia de las mujeres y fuentes orales, (Dossier) Arenal. Revista de Historia de las mujeres, vol. 4 n 2 (1997).

24. AGULHON: Maurice, Marianne au combat, L'imagerie et la symbolique républicaines (18801914), Paris, Flammarion, 1989. HOBSBAWM, Eric: «El hombre y la mujer: imágenes a la izquierda", en El mundo del trabajo. Estudios históricos sobre la evolución de la clase obrera, Barcelona, Crítica, 1987, pp. 117-143.

25. En España, BIHES: Bibliografía de Historia de España. III. Las mujeres en la Historia de España, Madrid, Centro de Información y Documentación Científica (CINDOC), Dpto. de Ciencias Humanas, 1994. ORTÍZ GÓMEZ, Teresa; BIRRIEL SALCEDO, Joanna; MARTIN PARRA, Victoria (eds.), Universidad y Feminismo en España (I). Bibliografía de Estudios de las Mujeres (1992-1996), Granada, Feminae, Universidad de Granada, 1998.

26. Ver, entre otros, AGUADO, A. y otras, Textos para la Historia de las mujeres en España. Madrid, Cátedra, 1994; DURÁN, Ma Angeles: Mujeres y hombres en la formación del pensamiento igualitario. Madrid, Castalia-Instituto de la Mujer, 1994; JAGOE, Catherine; BLANCO, Alda; ENRÍQUEZ DE SALAMANCA, Cristina, La mujer en los discursos de género. Textos y contextos en el siglo XIX. Barcelona, Icaria, 1998.

27. Ver Feminist Studies, Signs, Journal of Women in Cultura and Society, Journal of Women's History, en Estados Unidos; Gender and History (desde 1989 en adelante) y Women's History Review (desde 1992 hasta la actualidad), en Gran Bretaña; Women's Studies Internacional Forum, The European 
una esfera robada al mundo público, una noción que se define tanto por su correspondencia con su antónimo como por su radical diferencia con él ${ }^{28}$. O sea, que el principal punto de referencia de un ser social es lo público, por ser éste el ámbito del poder político; mientras lo privado se asocia al individuo como un espacio que se hurta a la mirada pero en el que penetra la civitas pese a todo; un espacio del que emana un poder que frecuentemente es connotado como contrapoder y del que se desprenden determinadas virtudes cívicas y formas de cultura política. No obstante, la individualidad acaba por diluirse en el marco de las jerarquizaciones que recorren los universos privados. Foucault ha llamado la atención sobre este hecho y afirma que "entre cada cuerpo social, entre un hombre y una mujer, entre un maestro y su alumno, entre el que sabe y el que no sabe, pasan relaciones de poder que no son la proyección pura y simple del gran Poder soberano sobre los individuos; son más bien el suelo movedizo y concreto sobre el que ese poder se incardina, las condiciones de posibilidad de su funcionamiento ${ }^{29}$.

El concepto de cultura femenina, aunque adopta formulaciones diversas, resulta muy útil para entender esta compleja malla de relaciones. En general, la noción abarca tanto el conjunto de saberes escritos y hablados como las prácticas sociales, tradiciones y rituales femeninos. A partir de este doble prisma puede cotejarse la experiencia del aprendizaje, la maestría, la transmisión de roles y las formas de conciencia que llevan a las mujeres a incidir en la vida y también a redefinir sus propias formas de vida. Este proceso implica un recorrido desde la cultura doméstica a la cultura política, considerando ésta tanto en un sentido amplio -conjunto de actitudes, valores y comportamientos cívicos que requieren unas pautas de socialización formales e informales, además de los mecanismos institucionales de participación y representación- como en un sentido feminista de cambio social capaz de impulsar redes sociales, asociaciones, solidaridades de grupo y diversas movilizaciones ${ }^{30}$. Sin género de dudas

Jorunal of Women's History y Women's History Today, también en el área anglosajona. D(onna), W(oman), F(emme), (desde 1976 en adelante), Memoria. Revista di storia delle donne (desde 1981 a 1993), Leggere Donna y Legendaria, en Italia: Penélope, pour l'histoire des femmes (1979-1985), Clio. Histoire, Femmes et Societés (1995 en adelante), Nouvelles Questions Féministes (desde 1981 hasta hoy), en Francia; Cahiers du Griff y Sextant. Revue du Groupe Interdisciplinaire d'Etudes sur les Femmes, en Bélgica ; Duoda. Revista de Estudios Feministas (a partir de 1991), Asparkía. Investigació Feminista (desde 1992 a la actualidad), Arenal. Revista de Historia de las Mujeres (desde 1994 hasta hoy), Feminismo/s, a partir del año 2003, en España.

28. BÉJAR, Hélène: El ámbito intimo. Privacidad, individualismo y modernidad, Madrid, Alianza Editorial, 1988.

29. FOUCAULT, Michel: op. cit., Madrid, La Piqueta, 1987.

30. Los debates historiográficos sobre el concepto de cultura femenina se centraron en sus orígenes en el área anglosajona. Ver SCOTT, Nancy: Te bonds of Womanhood: Women's sphere in New England 1780-1835, New Haven, Yale University Press, 1977. En relación con la cultura de la domesticidad y la teoría de las esperas pública y privada durante la época victoriana existe una abundante bibliografía. Remito a BRANCA, Patricia: "Image and reality: the Mith of Middle Victorian Woman", en M.S. HARTMANN; L. BANNER (eds.), Clio's consciousness raised. New perspectives on the History of women's, New York, Harper Colophon Books, 1974. Sobre las mu- 
la construcción del sujeto político mujer lleva implícita la transmisión de unas virtudes públicas, cívicas -capacidad de diálogo, resistencia, tolerancia, flexibilidad, mesura en la administración- puestas a prueba en el ámbito doméstico y ligadas a la búsqueda de una "felicidad social» que encuentra en el feminismo un excelente caldo de cultivo.

El género literario epistolar constituye un importante material para obtener información sobre la cultura doméstica y la cultura política. Citaré un ejemplo. La relectura de la correspondencia de Eloisa y Abelardo pone de relieve, según han reconocido desde perspectivas diferentes Etienne Gilson y María Zambrano, el extraordinario valor intelectual y el sentido de la independencia de la protagonista, muy poco acorde con los rasgos que definirían en un momento histórico muy posterior el ideal de la domesticidad ${ }^{31}$. La filósofa malagueña muestra a Eloísa como «una mujer lacerada entre la pasión que siente por el mundo del «espíritu»-el logos, el pensamiento filosófico como expresión de la virilidad que se construye socio-culturalmente- y la imposibilidad concreta de encontrar en él un lugar propio, una "sede» ${ }^{32}$. El ideal de amor-amiticia que defiende Eloísa exigiría considerar a la mujer como un ser semejante al hombre -semejante en la diversidad-, es decir un igual, algo prácticamente imposible en las pautas socioculturales de su época.

En general, las epístolas femeninas iluminan determinados aspectos relacionados con la privacidad de las mujeres: trabajos reproductivos, usos del tiempo, ejercicio de la maternidad -educación y socialización de los hijos-. Resultan imprescindibles para la construcción de retratos individuales y genealogías. En cualquier caso, el canon epistolar refleja las complejas relaciones entre ámbitos interiores y exteriores, con sus mutuas redes de influencias y sus condiciones cambiantes, reflejando que lo privado es político y que su incidencia en lo público es notable, pues es en la privacidad donde primero se interiorizan los roles sexuales y sociales, se manifiestan las ideologías y hasta cierta esquizofrenia socio-cultural que lleva a negar de puertas adentro algunos de los valores que se manifiestan y defienden de puertas afuera.

Se ha subrayado que los textos memorialísticos pueden ser considerados un ejemplo acabado de la cultura androcéntrica, ya que frecuentemente remiten a un sujeto histórico masculino volcado hacia lo público: las mujeres seguían estando adscritas, en un sentido real y simbólico, a la no-historia, es decir a

jeres y los hogares obreros, ver la traducción castellana del artículo de TILLY, Louise; SCOTT, Joan: "Mujer, trabajo y familia", en M. Nash, (ed.), Presencia y protagonismo. Aspectos de la Historia de la Mujer, Barcelona, Serbal, 1984. En el ámbito mediterráneo, FARGUE, Arlette: «La Historia de las Mujeres. Cultura y poder de las mujeres. Ensayo de historiografía", Historia Social n 9 , (1991). CORI, Paola di: "Cultura del feminismo. Il caso della storia delle donne in Italia", en Storia del'Italia republicana. Turín, Einaudi, vol. III, 1997.

31. GILSON, Etienne: Eloisa e Abelardo, Torino, Einaudi, 1950. ZAMBRANO, María: «Eloisa o la existencia de la mujer", en E. LAURENZI: María Zambrano. Nacer por sí misma, Madrid, Horas y Horas, 1995, pp. 90-113.

32. LAURENZI, Elena: op. cit., p. 81. 
lo privado ${ }^{33}$. Donna Stanton ha realizado un estudio pormenorizado sobre los textos memorialísticos escritos por aquéllas, calificando la voz femenina como "subalterna", y colonizada por la sociedad patriarcal, voz condenada al silencio la mayor parte de las veces o que asume su posición de hablante desde los márgenes del discurso ${ }^{34}$. Esa "colonización" se impuso en España con el respaldo de dos importantes instrumentos de control social: la Iglesia y la Familia. Sin embargo las prácticas descolonizadoras lograron soltar amarras durante la Segunda República, con la obtención del sufragio, el derecho de familia, la coeducación, la protección social de la maternidad y otras reformas. Al acabar la guerra civil, las mujeres formaron un colectivo segmentado por la clase social y por el hecho de pertenecer al bando de los vencedores o al de los vencidos. En caso de formar parte de este último no sólo perdieron las conquistas laboriosamente obtenidas durante la etapa republicana, sino que sufrieron una segunda pérdida, pues la Dictadura sepultó durante cuarenta años la memoria de lo acaecido.

Así, desde el exilio exterior o interior surge una tradición memorialística femenina que no tenía precedentes en el país, poco dado, por lo demás, al cultivo de estas formas literarias. En esos textos los hechos rememorados se alejan del "tradicional universo femenino", para mostrarnos numerosas heroicidades protagonizadas por las mujeres, sus vivencias, justificaciones políticas e ideológicas, así como testimonios de interés sobre el mayor drama histórico del siglo $\mathrm{XX}$ españo ${ }^{35}$. Los escritos autobiográficos femeninos sobre la guerra, el exilio y la cárcel constituyen también una forma privilegiada de fortalecer la identidad, o quizá de sobrevivir en un mundo hostil.

A menudo, la incapacidad para expresarse en voz alta arrastra a las mujeres a practicar la literatura autobiográfica. Sidonie Smith afirma que no importa el nivel de compromiso que la escritora adopte en su esfuerzo por representarse: el mismo acto de asumir el proceso de escritura significa en sí mismo un reto, un acto de poder, una forma de desorden ${ }^{36}$. No importa que, frente al canon clásico, las autobiografías femeninas encaren de manera diferente los contenidos y los aspectos formales, que el yo parezca descentrado, dividido, incluso ausente ${ }^{37}$, hecho que afecta -conviene recordarlo- no sólo a las mujeres

33. SMITH, Silonie: A poetics of women's autobiography. Marginality and the fiction of self representation, Bloomington, Indiana University Press, 1987.

34. STANTON, Domna C.: The female Autograph. Chicago, University of Chicago Press, 1984. Ver MANGINI, Shirley: Recuerdos de la Resistencia. La voz de las mujeres de la Guerra Civil española, Barcelona, Península, 1997

35. KENT, Victoria: Cuatro años en París (1940-1944). Edición Facsímil. Málaga, Universidad de Málaga, 1997. BERENGUER, Sara: Entre el sol y la tormenta. Treinta y dos meses de guerra (19361939), Barcelona, Seuba, 1998. MONTSENY, Federica: El éxodo (pasión y muerte de los españoles en Francia), Barcelona, Galba, 1977 y Mis primeros cuarenta años, Barcelona, Plaza y Janés, 1988; LEÓN, María Teresa: Memoria de la melancolía, Buenos Aires, Losada, 1970; IBARRURI, Dolores: El único camino, Moscú, Editorial Progreso, 1976.

36. SMITH, Sidonie (1987), op. cit.

37. BENSTOCK, Shari (ed.), The private self. Theory and practice of women's autobiographical selves, Chapel Hill, The University of North Carolina Press, 1988 
sino a los grupos oprimidos y las minorías en general. El yo que las mujeres suelen proyectar en sus memorias y diarios está conformado por su propia subjetividad y por una identidad colectiva que debe mucho a las imágenes de sí misma que se le han pretendido imponer históricamente. Uno de los rasgos característicos de esta escritura es la fuerza emocional que surge de determinadas situaciones.

En fin, como síntesis y aún constatando la importancia de las voces femeninas para reconstruir la Historia de las Mujeres, el timbre sexuado de los documentos no debe constituir un punto de partida inamovible sino más bien una puerta abierta a la reflexión y la resignificación. Lo más importante es organizar con los materiales una polifonía de voces, sonidos y matices.

\section{ESPACIOS DE CULTURA Y DE SABER FEMENINOS: LAS BIBLIOTECAS DE MUJERES}

Una forma de testimoniar el pasado de las mujeres y de mostrar que su trabajo y su pensamiento no han sido esporádicos ni errantes, y que no están huérfanos de una tradición propia, ha sido la creación de Bibliotecas de Mujeres. Estos espacios permiten comprobar que los escritos femeninos se inscriben en un "pasado histórico» e inciden en un "presente contextual». Además permiten ahondar en el conocimiento de la historia de las mujeres, recuperando los variados aspectos de su memoria colectiva. Al hacerlo, es inevitable adentrarse en el plano de las realidades tangibles, incluso en el del pensamiento utópico entendido como el "espacio y el tiempo de los deseos», como esperanza, ampliación y transformación de la realidad, búsqueda de la felicidad y del progreso. Utilizando los recursos de la literatura utópica, Cristina de Pizán construyó un recinto cultural para las mujeres y contrarrestó así el argumento misógino del no-saber femenino. Pero fueron muchas las escritoras que lograron adelantarse a su tiempo, o chocaron de frente con él, ejerciendo unas prácticas socioculturales que no eran bien vistas y que las llevaron a ser motejadas, en el mejor de los casos, con el sambenito de «marisabidillas», o que en el peor sirvieron para condenarlas por rebeldes y heterodoxas.

Un testimonio de esas prácticas culturales, básicamente de las escritas, son los fondos recogidos en las Bibliotecas de Mujeres. A partir de ellos, los saberes históricos en su conjunto se han visto sometidos a un proceso de reescritura al que no son ajenos los discursos sobre las identidades individuales y colectivas, las relaciones sociales de clase, etnia y género, así como la visión de un horizonte utópico que impregna el plano de las formulaciones teóricas y el de las vivencias cotidianas ${ }^{38}$. A partir de ellos - pero no solo con ellos- se ha redefinido lo social en términos políticos -educación, incorporación al mercado laboral,

38. Sobre estos aspectos, RAMOS, $M^{a}$.Dolores; VERA BALANZA, $M^{\mathrm{a}}$.Teresa (coords.): Discursos, realidades, utopias. La construcción del sujeto femenino en los siglos XIX y XX, Barcelona, Anthropos, 2002 , p. 7. 
beneficencia, filantropía, moralidad, formas de liderazgo y maestría- y una valoración sobre cómo se escribe la diferencia sexual en la Historia.

En Europa existen diversas bibliotecas y centros de documentación de mujeres, creados a partir de la iniciativa privada o del impulso de los grupos feministas. La primera de ellas fue la Biblioteca Popular de la Dona en Barcelona, fundada por Francisca Bonnemaison en 1909 e integrada hoy en la Red de Bibliotecas Públicas de la capital de Cataluña. Posee un valioso fondo sobre el período comprendido entre finales del siglo XIX y comienzos de la Guerra Civil española. Años más tarde, en 1926, surgiría en Londres The Fawcett Library (hoy Biblioteca Nacional de las Mujeres), a instancias de la London Society for Women's Service. Actualmente pertenece a la Universidad Guidhall de Londres, tiene un fondo de 60.000 volúmenes y cuenta con una importante colección de libros de historia. La Biblioteca Marguerite Durand, en París, se fundó en 1931 a partir de la colección particular de esta periodista francesa, que la donó al Ayuntamiento de la ciudad. Tiene más de 30000 volúmenes, enriqueciéndose constantemente mediante la donación de colecciones particulares y archivos de mujeres. En Amsterdam abrió sus puertas en 1935 el International Information Centre and Archives of the Women's Movement, un organismo privado, pero subvencionado por el gobierno holandés, cuyos fondos -más de 65.000 volúmenes- son básicos para el intercambio internacional de información sobre el movimiento feminista. La Biblioteca y Centro de Documentación de la Mujer, en Bolonia, creada a finales de los años setenta por la Asociación de Mujeres Orlando, es hoy la principal biblioteca autónoma de Italia. "Conviviendo» con ellas, las bibliotecas generales contienen en algunos países fondos de gran valor para reconstruir la historia de las mujeres. Es el caso, por citar un ejemplo, de la Biblioteca de Documentación Internacional Contemporánea, en París, que alberga el importante legado de la pacifista Gabrielle Duchène sobre las organizaciones católicas femeninas.

En nuestro país, las bibliotecas de mujeres comenzaron a emerger en las primeras décadas del siglo XX, ligadas a los proyectos intelectuales del feminismo social en sus dos vertientes, laica y católica. Estas corrientes promovían, ante todo, la educación de las mujeres, su incorporación al mercado laboral-siempre en trabajos «apropiados»-, la defensa de la maternidad biológica y social y un «rearme moral» mediante el concurso del elemento femenino. Un marco dual como el señalado propició la creación de redes culturales, fomentó el asociacionismo, la gestación de determinados movimientos sociales vinculados a la paz, y ya en los años veinte, la lucha sufragista, la consolidación de sindicatos específicamente femeninos y el movimiento intelectual de «las modernas». Íntimamente ligado a éste, tanto que podría considerarse causa y efecto a la vez del mismo, fue la fundación en Madrid, continuando el ejemplo de la Biblioteca Popular Francesca Bonnemaison, de la Biblioteca de la Residencia de Señoritas, creada en 1915 por María de Maeztu, a la que siguió la Biblioteca del Lyceum Club, fundada en 1926 por la escritora Isabel Oyárzabal de Palencia -futura embajadora española en Suecia-, Victoria Kent -futura Directora General de Prisiones-, la traductora Zenobia Camprubí, la escritora Carmen Baroja y la propia Maeztu, 
entre otras ${ }^{39}$. El Lyceum fue un espacio cultural, elitista, ajeno a cualquier forma de entender la política o la religiosidad y que pretendía formar el espíritu de las mujeres, facilitar el intercambio de ideas y encauzar las actividades sociales, artísticas, literarias y científicas que redundaran en beneficio de las socias ${ }^{40}$.

La guerra civil y la dictadura franquista truncaron, entre otras cosas, la trayectoria de la cultura letrada femenina, a la que se habían incorporado escritoras, lectoras y artistas del espacio intergeneracional que discurre entre 1917-1939. Nos referimos a las mujeres del 98, representadas por Carmen de Burgos, Sofía Casanova, Concha Espina, María Lejárraga, que tuvieron que afrontar la estrechez de miras de la sociedad de su tiempo; las mujeres de la generación del 14, la "primera generación» de universitarias españolas vinculada en gran medida a los planteamientos institucionistas, impulsora del primer asociacionismo sufragista en los años veinte -Asociación Nacional de Mujeres Españolas, Unión de Mujeres Españolas, Juventud Universitaria Femenina, Cruzada de Mujeres Españolas- y de un periodismo que sirvió de tribuna a sus ideas (la revista Mundo Femenino, Redención, entre otras). Mujeres que jugaron un papel relevante en lo público, pues a los nombres citados hay que añadir, sin ánimo de exhaustividad, los de la abogada Clara Campoamor, la pintora Maria Blanchard, la doctora Elisa Soriano, la crítica de arte y futura diputada socialista Margarita Nelken, la periodista, actriz y militante del partido federal Carmen Eva Nelken (Magda Donato), hermana de la anterior, la líder comunista Dolores Ibárruri, y el grupo de «mujeres del 27»: $M^{a}$ Teresa León, Rosa Chacel, Concha Méndez, Josefina de la Torre y Ernestina de Champourcín, la pintora Maruja Mallo, la pensadora María Zambrano. Más alejadas de estos círculos por su procedencia proletaria y su formación autodidacta, aunque compartiendo algunas de las características de su generación, destacan la poeta ultraísta Lucía Sánchez Saornil, una de las fundadoras de Mujeres Libres, y la escritora libertaria y futura ministra de sanidad Federica Montseny, ambas con una reconocida militancia en el ámbito anarquista.

Casi todas estas mujeres engrosaron el exilio republicano. Obviamente, hasta la transición democrática no se dieron las condiciones políticas para la creación de una nueva red de bibliotecas de mujeres. La coyuntura histórica propició la apertura de algunas salas de lectura vinculadas a los Seminarios e Institutos Universitarios de Estudios de la Mujer, a la vez que surgían otras Bibliotecas dependientes de la Administración central o autonómica y, sobre to-

39. MANGINI, Shirley: Las modernas de Madrid. Las grandes intelectuales españolas de la vanguardia, Barcelona, Península, 2000; AGUADO, Ana; RAMOS, Ma Dolores: La modernización de España (1917-1939). Cultura y vida cotidiana, Madrid, Síntesis, 2002.

40. Ver las recientes interpretaciones de CASTILLO MARTÍN, Marcia: Las convidadas de papel. Mujer, memoria y literatura en los años veinte. Premio de Investigación María Isidra de Guzmán. Alcalá de Henares, Ayuntamiento de Alcalá de Henares, 2001. FAGOAGA, Concha : "El Liceum Club de Madrid, élite latente ", en D. Bussy-Genevois (dir.): Les espagnoles dans l'histoire. Une sociabilité démocratique. (XIXe-XXe siècles), Saint-Denis, Presses Universitaires de Vicennes, 2002, pp. 145-167. 
do, los Centros de Documentación surgidos a instancias del propio movimiento feminista. Especial interés tiene, entre las salas de lectura señaladas, la Biblioteca de Mujeres de Madrid, creada en 1985 por la documentalista Marisa Mediavilla, un centro que tiene en la actualidad unos 15000 volúmenes entre los que se cuentan obras teóricas, biografías, documentos generados por el movimiento de mujeres en nuestro país y publicaciones periódicas de diverso signo ideológico: La Ilustración de la Mujer, Blanco y Negro, La Esfera, Medina y Baza, las dos últimas vinculadas a la Sección Femenina.

Mujeres enclaustradas para la Historia durante siglos. Mujeres desenclaustradas, visibles, reencontradas durante los últimos treinta años. Aunque estamos ante un importante hito cultural y político, el resultado no afecta sólo a la visibilidad de un sujeto histórico antaño «inexistente». El estudio de la contribución histórica de las mujeres nos adentra en un nuevo orden de conocimiento del que surgen enunciados y prácticas metodológicas desconocidas, nuevos temas y registros sobre la evolución histórica de la humanidad. Un orden histórico que aunque reconozca las herencias recibidas y utilice enfoques reconocibles, aporta innovadores elementos a la teoría de la Historia. 